\title{
Buenas prácticas para guiar la atención del espectador en el reportaje inmersivo con vídeo en $360^{\circ}$
}

\section{Best practices for guiding viewer attention in immersive feature with $360^{\circ}$ video}

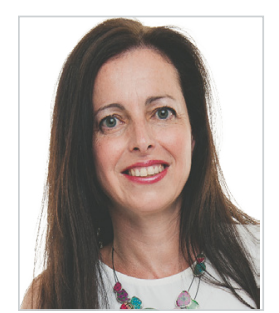

María José Benítez de Gracia. Licenciada en Periodismo (Universidad Europea de Madrid), Máster en Investigación Aplicada a Medios de Comunicación (Universidad Carlos III de Madrid, 2016) y Doctora en Investigación en Medios de Comunicación (Universidad Carlos III de Madrid, 2019). Premio Extraordinario de Doctorado, su tesis está centrada en el reportaje inmersivo con vídeo en $360^{\circ}$. Forma parte del Grupo de Investigación "Innovation on Digital Media”, dedicado a la innovación mediática en entornos digitales, dentro del departamento de Comunicación de la Universidad Carlos III de Madrid. Su investigación está ligada a las narrativas inmersivas en el contexto de la innovación mediática. Actualmente, es profesora de Narrativa audiovisual en la Universidad Isabel I.

Universidad Isabel I, Burgos, España

mariajose.benitez@ui1.es

ORCID: 0000-0002-1101-004X

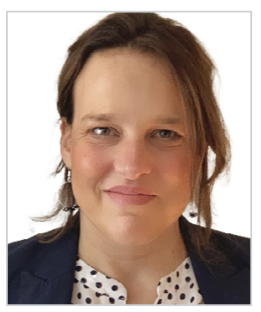

Susana Herrera Damas. Licenciada en Comunicación Audiovisual (Universidad de Navarra, 1998) y en Sociología (UNED, 2004) y Doctora en Comunicación Audiovisual (Universidad de Navarra, 2002). Premio Extraordinario de Doctorado, en la actualidad es Profesora Titular de Periodismo en la Universidad Carlos III de Madrid, donde investiga buenas prácticas de iniciativas emergentes relacionadas con la innovación periodística. Ha sido Visiting Scholar en las Universidades de Ottawa (Canadá), Texas en Austin (Estados Unidos) y en la Missouri Journalism School (Estados Unidos). En la actualidad, dirige el grupo de investigación Innovation on Digital Medial y el programa de doctorado en Investigación en Medios de Comunicación en la Universidad Carlos III de Madrid. Universidad Carlos III de Madrid, España

dherrera@hum.uc3m.es

ORCID: 0000-0002-1755-1621

Recibido: 21/12/2020 - Aceptado: 24/02/2021 - En edición: 24/03/2021 - Publicado: 14/06/2021

\section{Resumen:}

El reportaje inmersivo con vídeo en $360^{\circ}$ supone una nueva forma de mostrar los acontecimientos que convierte al espectador en un testigo directo o, incluso, en el protagonista de una realidad que se representa. El espectador accede a un entorno de $360^{\circ}$ y adquiere
Received:21/12/2020 - Accepted: 24/02/2021 - Early access: 24/03/2021 - Published: 14/06/2021

\section{Abstract:}

Immersive feature reporting with $360^{\circ}$ video is a new way of presenting events that transforms the viewer into an eyewitness, or even the main character, of a reality that is being portrayed. Due to the immersive aspect it provides (both technical and narrative),

1 Acción financiada por la Comunidad de Madrid en el marco del convenio plurianual con la Universidad Carlos III Madrid en su línea de actuación Excelencia para el Profesorado Universitario

Cómo citar este artículo:

Benítez de Gracia, M. J. y Herrera Damas, S. (2021). Buenas prácticas para guiar la atención del espectador en el reportaje inmersivo con vídeo en $360^{\circ}$. Doxa Comunicación, 32, pp. 263-287.

https://doi.org/10.31921/doxacom.n32a13 
una perspectiva en primera persona cuyo punto de vista controla a su voluntad. Sin embargo, en la práctica, este poder se encuentra con un obstáculo ya que, en numerosas ocasiones, el periodista no puede dirigir su atención tal y como ocurre en vídeo convencional. El objetivo de esta investigación es identificar una serie de prácticas que permitan dirigir la atención del espectador sin privarle de la facultad de controlar el punto de vista. Para ello, hemos realizado una exhaustiva revisión de la literatura sobre el tema, hemos visionado más de mil reportajes de este tipo y hemos llevado a cabo 9 entrevistas en profundidad con expertos, profesionales y académicos. Con todo ello, hemos identificado 4 buenas prácticas que pueden contribuir a este fin. El presente estudio justifica la necesidad de cada una de ellas e ilustra sus posibilidades con ejemplos reales extraídos de reportajes producidos por medios de referencia.

\section{Palabras clave:}

Periodismo inmersivo; reportaje; vídeo en $360^{\circ}$; buenas prácticas; atención. the viewer enters $a 360^{\circ}$ environment and acquires a first-hand perspective with a vantage point that he or she can control at will. In practice, however, this power is hindered by the fact that on many occasions the journalist is unable to direct the viewer's attention in the same way as can be achieved with conventional video. The aim of this study is to identify a series of practices that allow the viewer's attention to be directed without depriving him or her of the power to control the point of view. To achieve this purpose, an exhaustive review of the literature on the subject has been conducted, more than a thousand reports of this type have been viewed, and nine in-depth interviews with experts, professionals and academics have been carried out. As a result, we have identified four types of best practices that can help in achieving this purpose. This study justifies the need for each of them and illustrates their potential with reallife examples taken from reports produced by benchmark media.

Keywords:

Immersive journalism; feature; $360^{\circ}$ video; best practices; attention.

\section{Introducción}

En periodismo, las narrativas inmersivas han permitido mostrar los acontecimientos de un modo muy realista y acercar así más al espectador a la historia (De la Peña et al. 2010: 292). Este nuevo formato permite representar el espacio de un modo continuo y sin límites rompiendo con el encuadre clásico. El espectador se sitúa en el centro de un escenario esférico y obtiene un punto de vista en primera persona que puede controlar libremente, moviendo y girando la cabeza, experimentado una sensación como si realmente se encontrara en el lugar en el que ocurre la acción (Aronson-Rath et al., 2015; Dolan \& Parets, 2015; Doyle et al., 2016; Sirkkunen et al., 2016; Sidorenko et al., 2017: 103; Hardee \& McMahan, 2017: 4; Jones, 2017). Este logro se debe sobre todo al impulso y a la convergencia de una serie de tecnologías inmersivas (Oculus, 2014 y 2015; Google, 2015 y 2016) que, en los últimos 6 años, han sido muy apoyadas por las grandes plataformas de Internet (Google, 2015; Facebook, 2014 y 2015).

El uso combinado de un visor estereoscópico y el formato de vídeo en $360^{\circ}$ genera en el espectador la ilusión de acceder a un espacio tridimensional que ofrece una experiencia visual, auditiva e incluso táctil (Pryor, 2010). A su vez, esta representación se apoya en el uso de unos recursos narrativos estéticos e interactivos que conforman la acción entre el espectador y el relato (Domínguez, 2010). Esta nueva tecnología se ha comenzado a aplicar en distintos ámbitos como el educativo, el inmobiliario, el turístico, o el publicitario (Clark, 2015).

Desde 2015 se emplea también en periodismo. Numerosos medios, tanto nacionales como internacionales, han adoptado este formato. Entre algunos de los más relevantes, podemos encontrar a The New York Times, The Guardian, Associated 
Press, USA Today, The Washington Post, ABC News, Wall Street Journal, Discovery Channel, National Geographic, BBC, Euronews, RTVE y El País. Destaca el ejemplo de The New York Times que cuenta con una sección específica, The Daily 360 (Hardee \& McMahan, 2017: 2), dedicada a la producción diaria de piezas inmersivas. Hasta enero de 2018, sumaba un total de 371 piezas (Uskali et al., 2021: 14). Del mismo modo, varios periodistas independientes han mostrado también un gran interés en la producción de este tipo de contenidos (Sidorenko et al., 2020: 118).

A su vez, la novedad que incorpora esta nueva narrativa implica un modelo de producción complicado y costoso (Uskali et al., 2021: 18), un cambio radical de los propios dispositivos técnicos empleados para grabar y editar los contenidos (Doyle et al., 2016; Hardee \& McMahan, 2017: 6), nuevos desafíos éticos (Kent, 2015; Gregory, 2016; Kool, 2016; Madary \& Metzinger, 2016; Nash, 2018; Sánchez Laws \& Utne, 2019 y Pérez-Seijo \& López García, 2019), el empleo de aplicaciones específicas para su difusión (Colussi \& Reis, 2020: 29) y, en definitiva, todo un replanteamiento de la propia estructura narrativa (Lelyveld, 2015; Aronson-Rath et al., 2015).

A cambio, poder visualizar un contexto más completo a través de un escenario en $360^{\circ}$ ofrece nuevas posibilidades que no hemos encontrado hasta la fecha en medios audiovisuales convencionales. La supresión de los límites del encuadre tradicional (Watson, 2017: 22; Marconi \& Nakagawa, 2017: 3; Sánchez Laws, 2019: 33) permite al espectador visualizar los acontecimientos dentro de un espacio sin rupturas, representado de forma continua en un escenario de $360^{\circ}$, lo que mejora su experiencia informativa. Esto puede otorgar una mayor credibilidad a los hechos y contribuir a recuperar a una audiencia cada vez más fragmentada (Pavlik, 2005: 40), viral (Martínez Rodríguez \& Torrado, 2017: 148) e inclinada a consumir la información a través de dispositivos móviles (Salaverría, 2015: 149).

La posibilidad de que sea el espectador quien controle el punto de vista surge, así, como una de las señas de identidad del periodismo inmersivo. No obstante, esta peculiaridad se encuentra en la práctica con dos obstáculos. Por un lado, la propia novedad y el manejo del dispositivo de visualización pueden distraer. Con todo, se trataría de un problema menor, que disminuye conforme el espectador se vaya familiarizando con este tipo de dispositivos (Syrett et al., 2017: 206). La segunda dificultad se plantea a la hora de crear una narrativa coherente ya que, en esta modalidad, el director no puede controlar la atención del espectador ni dirigir su mirada como ocurre en otras narrativas audiovisuales convencionales (Nielsen et al., 2016: 229).

Hacerlo rompería con uno de los rasgos básicos de este tipo de periodismo. Además, en ocasiones, la limitación para dirigir la atención es incluso técnica ya que este formato no permite utilizar algunos de los recursos que emplea la narrativa audiovisual tradicional como, por ejemplo, los primeros planos, el encuadre o el enfoque o desenfoque de objetos. Junto a estos condicionantes, también se debe tener en cuenta que el movimiento no controlado por el espectador mediante una cámara en movimiento puede generar malestar o mareo (Nielsen et al., 2016: 231; Hardee \& McMahan 2017: 7; Bailenson, 2018; Fagan, 2018; Uskali et al., 2019: 52). 


\section{Metodología empleada}

En este contexto, el objetivo de esta investigación parte de la necesidad de identificar una serie de prácticas dentro de las narrativas inmersivas que permitan que, en determinados momentos, el director pueda guiar la atención del espectador sin privarle por ello de controlar el punto de vista.

Para ello hemos llevado a cabo una exhaustiva revisión bibliográfica sobre el tema en las bases de datos Web of Science, ProQuest, Ebsco, y Google Scholar. En concreto, hemos utilizado las siguientes palabras clave (en inglés y en español): immersion, $360^{\circ}$ video, virtual reality, presence, immersive journalism y media innovation. Entre los resultados se incluyen varios estudios empíricos realizados hasta la fecha. Además, añadimos el visionado de más de mil reportajes de estas características publicados por medios periodísticos nacionales e internacionales durante el período comprendido entre 2015 y 2020.

En un segundo momento, hemos querido enriquecer esta búsqueda documental con la realización de 9 entrevistas semiestructuradas abiertas ${ }^{2}$ por la precisión y riqueza de detalles que aporta esta técnica de investigación (Wimmer y Dominick, 1996: 158). Pretendemos así triangular los resultados, "para llegar a conocer plenamente la naturaleza del tema sometido a investigación" (Wimmer y Dominick, 1996: 51).

Los entrevistados seleccionados responden a perfiles con implicación directa en este formato, bien por tratarse de profesionales que producen reportajes inmersivos o bien por ser académicos que los examinan a fondo. Tras seleccionarlos, elaboramos una guía provisional con las posibles preguntas que queríamos abordar, estructuradas en torno a los siguientes 4 bloques:

i. trayectoria personal en relación con el periodismo inmersivo

ii. tecnología de grabación y producción en vídeo $360^{\circ}$

iii. características narrativas generales del periodismo inmersivo

iv. pasado, presente y futuro del periodismo inmersivo

Este primer cuestionario fue revisado por dos profesores doctores de la Universidad Carlos III de Madrid, que añadieron algunos matices e incluyeron también ideas que habían quedado fuera. Realizados los correspondientes ajustes, obtuvimos el guion final de las preguntas. Posteriormente, se lo enviamos por correo electrónico a los entrevistados para que contaran con cierto margen de tiempo por si querían pensar sus respuestas. De este modo, pretendíamos evitar que tuviesen que contestar de manera espontánea y sin madurar mínimamente sus intervenciones puesto que, por la misma novedad que presenta el formato, convendría que algunas de las preguntas fuesen desarrolladas sobre la base de un razonamiento anterior. Las entrevistas fueron llevadas a cabo entre diciembre de 2015 y junio de 2018. Cada entrevista duró cerca de una hora.

2 Los entrevistados han sido: Xavier Conesa (director de Visyon), Adriano Morán (director de 93 Metros), Miriam Hernanz (subdirectora de Lab RTVE), Javier Coloma (director de Zakato 360), Ignacio Ferrando (director de Ábaco Digital), Daniel Rojas (director de 3GO Video), Robert Hernández (profesor e investigador sobre las narrativas inmersivas en la University of Southern California), Sara Pérez- Seijo (doctoranda e investigadora sobre el tema en la Universidad de Santiago de Compostela) y Antonio Baía Reis (doctorando e investigador sobre el tema en la Universidad de Porto, en Portugal). 
Después de transcribirlas, identificamos los nodos o palabras clave en cada una de ellas, resaltando los diferentes párrafos o añadiendo anotaciones que nos permitiesen reconocer e identificar fácilmente los aspectos tratados. Ordenamos la información que obtuvimos en fichas previamente divididas en función de los asuntos abordados. Realizamos este proceso varias veces con la idea de no dejar fuera ningún asunto importante.

Una vez triangulados los resultados, logramos sistematizar 4 buenas prácticas para guiar la atención del espectador en este tipo de narrativas. Antes de presentarlas, describiremos muy brevemente la novedad que supone el reportaje inmersivo con vídeo en $360^{\circ}$, por ser el género en el que hemos centrado la investigación.

\section{La atención del espectador en el reportaje inmersivo con vídeo en $360^{\circ}$}

Surgido a partir de 2015 de la confluencia de una serie de innovaciones tecnológicas (Benítez y Herrera, 2018), el reportaje inmersivo con vídeo en $360^{\circ}$ se puede definir como un:

"Modelo de representación de la realidad que narra y describe hechos y acciones de interés humano a partir de imágenes reales grabadas con vídeo en $360^{\circ}$ y que se sirve de técnicas de inmersión para generar en el espectador la ilusión de estar presente en el acontecimiento con una perspectiva en primera persona desde la que puede entender mejor las circunstancias, identificarse con los protagonistas e, incluso, experimentar las emociones que acompañan la realidad que está siendo representada" (Benítez y Herrera, 2017).

Como hemos señalado, uno de los elementos que permiten generar esta representación es la facultad otorgada al espectador para controlar el punto de vista y fijar su atención en aquello que le interese. En la práctica esto plantea una dificultad, tal como se refleja en los diferentes testimonios de los entrevistados.

Para Javier Coloma, director artístico de vídeo $360^{\circ}$ en zakato.com, esta mayor libertad con la que, en principio, cuenta el espectador se puede encontrar con limitaciones ya que, en determinados momentos de la narración, se podría perder partes importantes de la acción:

"Las producciones de siempre están diseñadas con anterioridad para guiar al usuario y conseguir que entienda lo que se le está contando [...] En las nuevas producciones la dificultad aumenta: el espectador es quien elige cómo observar el entorno $360^{\circ}$ y se puede perder la acción que se desarrolla en otro ángulo. Conseguir dirigir su libre albedrío visual es la cuestión más difícil de resolver" (Coloma, 2016).

A su vez, esta cuestión compromete cada una de las distintas etapas del proceso de dirección. A este respecto, varios entrevistados coinciden en que la planificación de las diferentes secuencias en la narrativa en $360^{\circ}$ plantea diversas dificultades:

"Hay que plantear los planos de manera distinta, saber qué sistema emplear, intentar evitar los movimientos bruscos, saber dónde puede haber acción y dónde no (hay un efecto conocido como parallax que complica mucho las cosas). Hay que desaprender todo lo aprendido" (Morán, 2016). 
"En un guion, en cualquier rodaje en $360^{\circ}$, nunca puedes estar seguro de que el usuario va a tener la experiencia que quieres que tenga. Cada experiencia es única, porque a lo mejor estás poniendo un rótulo ahí y él está mirando para allá y se pierde esa información. Por ejemplo, no hay primeros planos en $360^{\circ}$. Nunca vas a poder ver la expresión de una cara en $3 D^{\prime \prime}$ (Hernanz, 2016).

"La gran dificultad que hay con los guiones de $360^{\circ}$ es que el usuario puede mirar donde le dé la gana. No es lo mismo en un guion normal, donde el guionista decide lo que va a ver. Aquí no. No funciona. Aquí el usuario, básicamente, va a mirar donde quiera" (Ferrando, 2016).

Así, por ejemplo, la elaboración del guion debe contemplar que, durante la fase de grabación y en la posterior de montaje, no se puede recurrir a los cambios en el tipo de plano ni tampoco a recursos como el zoom o la profundidad de campo para enfocar o desenfocar determinadas zonas:

“No existen planos cortos como tal, ni el zoom adelante y atrás. Los travelling de seguimiento deben tener sentido para no marear. Los planos $360^{\circ}$ deben durar más tiempo para contextualizar, ya que el espectador debe saber dónde está y darse cuenta de la posibilidad de mirar en $360^{\circ}$ " (Coloma, 2016).

En este mismo sentido, la edición por corte supone una dificultad añadida, por lo que es frecuente que se recurra al plano secuencia:

"Muchas veces tenemos movimientos rápidos y cuesta hacer el stiching si hay mucho movimiento cerca y lejos de la cámara. No hay un detrás en vídeo $360^{\circ}$ [...] No vale el corte, no vale tener a alguien detrás que te diga lo que tienen que hacer los actores. Cuando empiezas a grabar, grabas hasta el final. Nosotros trabajamos con planos secuencia, normalmente, porque no se puede jugar con distintas cámaras: estás siempre viendo todo lo que está tu alrededor" (Conesa, 2016).

Para Xavier Conesa, director de proyectos de Visyon, la narrativa inmersiva implica todo un cambio en la forma de narrar ya que, a pesar de "escoger la ubicación de la cámara, no se puede evitar que el espectador vea todo lo que está pasando alrededor de ella":

"El storytelling clásico del cine ya no nos sirve. La experiencia clásica del usuario del televisor, del móvil, del portátil tampoco sirve. Estamos ante un nuevo dispositivo donde el usuario vive unas experiencias y donde no hay nada escrito y vamos abriendo camino [...] En $360^{\circ}$ el usuario siempre es libre de mirar donde quiera. Cada uno vive su experiencia dentro de ese vídeo. No es una experiencia dirigida. Te acompaña en la experiencia, pero el espectador es libre de hacer lo que quiera" (Conesa, 2016).

Pese a ello, en determinados momentos resulta necesario guiar la atención hacia una parte concreta de la escena. En varios de estos reportajes se ha optado por dirigir la cámara, limitando así la facultad que otorga este formato al espectador. Por ejemplo, el reportaje “The Atomic Bombing of Hiroshima”, publicado por The New York Times, fuerza el movimiento de la cámara para guiar al espectador por distintas áreas de un mapa lo que reduce la libertad que se le concede y termina por confundirle. Además, esta práctica hace que el espectador pueda experimentar una sensación de malestar o mareo, lo que a su vez disminuye su ilusión de presencia (Nielsen et al., 2016: 231; Hardee \& McMahan; 2017: 7; Narciso et al., 2019). 
Para evitarlo, resulta conveniente revisar algunas contribuciones basadas en el proceso de atención humana por si las lecciones aprendidas para los contenidos audiovisuales convencionales pudiesen arrojar algo de luz a la hora de establecer criterios válidos aplicables al vídeo en $360^{\circ}$.

La palabra atención proviene de la raíz latina attentus, de attendere, formada por el prefijo ad -que significa proximidad-y el verbo tendere-tender o estirar-. El uso de este término difiere en castellano y en inglés ya que, en el primer caso hace referencia a ayudar y, en el segundo, al acto de estar presente. Este último se ajusta más a la definición que buscamos.

Siguiendo a Goldstein, la atención es "uno de los mecanismos primarios que empleamos para enfocar las cosas importantes del entorno que de otro modo nos perderíamos” (Goldstein, 2007: 131). Algunos estudios evidencian que, en ocasiones, no percibimos la existencia de estímulos a los que miramos directamente sin prestar atención (inattentional blindness) o tenemos dificultad para advertir cambios entre dos escenas (change blindness). A este respecto, Goldstein sostiene que una de las causas por las que no percibimos estos cambios es porque tenemos la experiencia del pasado de que

"los cambios bruscos raramente aparecen en la vida real y, cuando lo hacen, normalmente, nos damos cuenta. Dado que los primeros suelen estar acompañados por un movimiento que crea una señal que atrae nuestra atención, si no atendemos a este movimiento, se pierde el cambio" (Goldstein, 2007: 127).

Goldstein recuerda la importancia de "vincular las distintas características de un objeto, como el color, la forma, el movimiento y la localización, para que, combinadas, creen la percepción de un objeto coherente" (Goldstein, 2007: 131).

Una de las teorías que explican cómo se genera este vínculo es la de la búsqueda visual (visual search), definida como lo "que hacemos cada vez que buscamos un objeto entre una serie de objetos" (Goldstein, 2007: 134). Según ésta, existe una búsqueda basada en una característica del objeto y otra búsqueda de conjunción que requiere que se combinen dos o más características.

Desde una perspectiva similar, Itti sostiene que "la atención visual se ve atraída hacia ubicaciones visuales sobresalientes" (Itti, 2017: 3227). Este autor utiliza el concepto de relevancia visual para denominar a "la cualidad perceptiva subjetiva que hace que algunos estímulos destaquen entre otros elementos o ubicaciones" (Itti, 2017: 3327). A su juicio, un objeto de color rojo aislado en un campo verde o un triángulo de emergencia serán sobresalientes y captarán la atención hacia al punto de la escena en el que se encuentran.

El lenguaje audiovisual ha trasladado estos conocimientos al cine y a la televisión. En su propuesta, Bordwell y Thompson sistematizan distintas técnicas cinematográficas que permiten al director controlar la narración y guiar la atención. Éstas pueden hacer alusión al proceso de filmación, a la puesta en escena, al sonido y al montaje de las imágenes. En concreto, los aspectos vinculados a la puesta en escena "atraen nuestra atención mediante los cambios de luz, forma, movimiento y otros aspectos de la imagen” (Bordwell y Thompson, 1995: 163). A su vez, estos autores dividen en cuatro categorías los distintos modos en los que el director puede guiar la atención del espectador mediante la puesta en escena (Bordwell y Thompson, 1995: 164): 
1. movimiento,

2. diferencias de color

3. equilibrio de los diferentes componentes y

4. variaciones de tamaño

En referencia al movimiento, estos autores destacan la facilidad de los objetos en movimiento para atraer la atención. Añaden como ejemplo el acto de agitar un periódico sobre una escena inmóvil. Por el contrario, cuando en la imagen coexisten varios objetos móviles, el espectador traslada su atención hacia ellos, de acuerdo con otras pistas o según sus expectativas sobre lo más destacado de la acción narrativa (Bordwell y Thompson, 1995: 164). Las diferencias de color también condicionan la percepción del espacio ya que, por ejemplo, los colores brillantes atraen la mirada frente a fondos más tenues. Asimismo, la luminosidad de los colores cálidos (rojo, naranja y amarillo) atrae más la atención que la de los fríos (morado, azul o verde).

La neurociencia denomina captación sensorial a la "utilización de una serie de recursos neuronales y psicológicos para centrar el foco de atención en un punto determinado" (Macknik y Martínez-Conde, 2012: 97). Siguiendo esta idea, ante dos movimientos, el ojo humano seguirá el que sea más prolongado y visible, un recurso que, por ejemplo, utilizan los magos cuando "muestran una paloma que aletea fuertemente para atraer la atención hacia ella y evitar que miren hacia el área donde preparan el truco" (Macknik y Martínez-Conde, 2012: 98).

Igualmente, a través de la denominada atención conjunta es posible "compartir la experiencia de otra persona siguiendo la dirección de su mirada y de sus gestos" (Macknik y Martínez-Conde, 2012: 89). Para ello, es recomendable que se enmarque "dentro de una acción natural como, siguiendo el ejemplo de los magos, rascarse la cabeza, beber un trago de agua, ajustarse las gafas o colgar una chaqueta” (Macknik y Martínez-Conde, 2012: 103).

Aunque la aplicación de estas técnicas al vídeo en $360^{\circ}$ todavía no ha sido suficientemente estudiada, la literatura académica basada en técnicas experimentales ofrece resultados prometedores que permiten extraer varias buenas prácticas.

Los estudios de Peck y su equipo confirman la idoneidad de integrar elementos distractores de forma natural. Señalan, por ejemplo, el vuelo de una mariposa sobre el escenario como recurso adecuado para guiar la atención hacia un punto concreto (Peck et al., 2009: 387). De acuerdo con las teorías expuestas, la atención del espectador se dirigirá hacia el elemento en movimiento, sin reducir la libertad de controlar el punto de vista, lo que otorga realismo y favorece la presencia. A este respecto, Nielsen y sus colaboradores plantean tres posibles alternativas para guiar la atención en un entorno virtual (Nielsen et al., 2016: 229):

1) mantener la escena el tiempo necesario para que el espectador la recorra con su mirada

2) presentar los objetos dentro de su campo de visión, y

3) añadir ciertas señales que permitan dirigir su atención hacia eventos y objetos relevantes 
Estas ideas se pueden trasladar al reportaje inmersivo con vídeo en $360^{\circ}$. La primera se refiere a la conveniencia de mantener la escena el tiempo suficiente para que el espectador la pueda recorrer en su totalidad, tal y como advierte Conesa:

"El gran handicap es la duración de las experiencias. No sabemos cuánto puede durar una experiencia para que no se canse el usuario. Con las Samsung Gear VR, una experiencia normal de tres minutos, el usuario solo contemplando tres, cuatro o cinco minutos lo que pasa, bien. A partir de cinco minutos, se hace pesado" (Conesa, 2016).

Precisar este cálculo es difícil dado que depende de la voluntad del propio espectador quien, a su vez, estará condicionado por una serie de factores: su experiencia previa con el sistema de visualización, el interés por el tema que aborde el reportaje, la acción que exista alrededor de $\operatorname{los} 360^{\circ}$ y los personajes u objetos que atraigan su atención. Es importante tener en cuenta, que, al contrario, una dilatación temporal podría generar un efecto contrario si, tras recorrer la escena, el espectador se encuentra con que no ocurre nada. Para evitar esta situación -y el consiguiente desinterés y apatía que esto pudiese generar- cabe añadir una voz en off que le guíe y anime a continuar.

La segunda alternativa consiste en limitar el número de objetos situados frente al campo de visión del usuario. Los experimentos de Logan Dwight, director de la productora estadounidense The Soap Collective, sugieren que la atención está relacionada con la ubicación y el enfoque. Partiendo de que el espectador suele visualizar estos contenidos sentado, Dwight limita la acción y recomienda que ésta no abarque todo el escenario esférico porque crearía confusión y ruido (Dwight, 2016) ${ }^{3}$.

Finalmente, la tercera alternativa se refiere al empleo de ciertas señales -implícitas o explícitas- para guiar la atención hacia objetos relevantes (Nielsen et al., 2016). A su vez, estas señales pueden formar parte de la narración (señales diegéticas) o tratarse de elementos externos (señales no diegéticas o extradiegéticas). En este último caso, se podría romper la sensación de presencia al resaltar la naturaleza mediada de la representación. Es lo que ocurriría, por ejemplo, si se añade un botón o flecha que parpadee o que tenga algún color llamativo. Los autores distinguen también si limitan o no la capacidad del usuario de interactuar dentro del entorno (Nielsen et al., 2016: 229). Al probar estos recursos sobre 45 participantes, detectaron que introducir un elemento guía como una luciérnaga en movimiento provocaba claves explícitas y no limitaba la interacción, por lo que recomiendan prácticas de esta naturaleza.

Varios estudios han probado la eficacia de otros recursos. Veas y sus colaboradores aplican una técnica conocida como "realidad mediada". Consiste en modificar durante la post producción ciertas características del mundo real con la intención de dirigir sutilmente la atención del usuario hacia un área, en lugar de emplear indicaciones gráficas como flechas o botones:

"aumentar el contraste entre algunas características como, por ejemplo, la luz, el color, el movimiento o el audio convierte a los objetos en partes más relevantes o destacadas en la escena para que el espectador pueda dirigir hacia allí su mirada” (Veas et al., 2011: 11).

3 En https://uploadvr.com/vr-film-tips-guiding-attention 
Brillhart (2016) denomina punto de interés (en inglés point of interest-POI-) a un elemento dentro de la narración que atrae la atención del espectador. Este tipo de recurso puede ser muy evidente-como un punto rojo o de alta intensidad- 0 más complejo -como una figura o un personaje que realice alguna acción-. No obstante, la autora también recuerda que la ilusión de presencia podría disminuir si la señal resultase muy explícita:

“cuanto más visible sea una señal, mayor será la probabilidad de que el espectador dirija su atención hacia ella, pero la experiencia de presencia será menor. Al contrario, cuanto menos obvia sea la señal, mayor será la probabilidad de que se sienta atraído de forma natural -que es el objetivo- pero también es menos probable que el espectador la considere como tal y responda hacia ella" (Brillhart, 2016) ${ }^{4}$.

Los estudios de Tecnic confirman que, para guiar la atención de un modo eficiente, la producción con vídeo en $360^{\circ}$ requiere combinar técnicas de grabación junto con otras de post-producción. Entre las primeras destacan los gestos, el guiado por voz y otro tipo de sonidos (Tecnic, 2018: 38). Entre las de post-producción, Tecnic propone el uso de:

a) gráficos (líneas guía, cajas de texto y títulos)

b) iluminación (contraste claro/oscuro y foco de luz) y

c) color (uso de colores diferentes o círculo rojo resaltado).

Los resultados de su investigación concluyen que emplear gráficos es una de las técnicas más adecuadas para atraer la atención. También destaca el uso de líneas guía, que se pueden complementar con otros elementos como cuadros de texto y títulos. En cuanto a las técnicas de iluminación, resalta el foco direccional y el cambio de contraste. El foco de luz parece ser la técnica más efectiva mientras que la utilización en simultáneo de los dos recursos podría resultar demasiado forzada para el espectador, restándole libertad a la hora de explorar el escenario (Tecnic, 2018: 38).

Por su parte, Rothe y Hußmann llevaron a cabo un experimento en el que aplicaron efectos de luces, sonidos y movimientos diegéticos para valorar hasta qué punto servían para atraer la atención. Los resultados mostraron una mayor eficacia de los objetos en movimiento y del sonido, incluso si se trata de audio no espacial o proviene de otra dirección. Además, el sonido resulta más eficaz si va unido a un objeto. Respecto a la iluminación, las luces estáticas no parecen especialmente efectivas, pero el foco de luz dirigido hacia un área concreta resultó el segundo recurso más eficaz (Rothe y Hußmann, 2018: 101).

Para medir la mayor o menor eficacia de todas estas técnicas, emplearon mapas de calor sensibles a través de un sistema de seguimiento de la mirada de los participantes en las distintas escenas que visualizaron. En la primera se examinaron tres objetos con señales diferentes de luz, movimiento y sonido: el casquillo iluminado de una bombilla, un cucharón en movimiento y el sonido de una gota de agua. El mapa de calor no mostró una atención significativa hacia ninguno ellos. En la segunda escena se incluyeron tres objetos con diferentes señales: una lámpara que parpadeaba, una olla sobre el fuego y un reloj que hacía tictac. Los puntos de mayor acceso fueron aquellos acompañados de sonido, mientras que la lámpara no captó la atención de los participantes. En la tercera escena, los objetos con sonido espacial aparecían y desparecían:

4 Disponible en https://medium.com/the-language-of-vr/in-the-blink-of-a-mind-attention-1fdff60fa045, fecha de la última consulta: diciembre de 2020 . 
un reloj con alarma, una tetera que silbaba y un reloj de cuco. En los tres casos la atención fue igual de significativa y cada participante cambió la mirada al aparecer un nuevo objeto con sonido (Rothe y Hußmann, 2018: 107-109).

\section{Buenas prácticas para guiar la atención del espectador en el reportaje inmersivo con vídeo en $360^{\circ}$}

A partir de estos hallazgos y de las reflexiones de los expertos entrevistados, sistematizamos una serie de buenas prácticas orientadas a guiar la atención sin disminuir la capacidad inmersiva ni la ilusión de presencia. Son éstas (Benítez y Herrera, 2020):

i. añadir en la escena elementos con movimiento

ii. emplear técnicas adecuadas de iluminación y color

iii. integrar elementos gráficos, $\mathrm{y}$

iv. aplicar sonidos espaciales a objetos.

\subsection{Añadir en la escena elementos con movimiento}

En vídeo convencional, el empleo de elementos en movimiento constituye un recurso adecuado para guiar la mirada del espectador hacia un punto concreto. No obstante, esta técnica precisa ser matizada cuando se trata de vídeo en $360^{\circ}$. En primer lugar, la propia tecnología de grabación impide el uso de algunos recursos, como el enfoque, el zoom o proponer escalas de plano para centrar la atención en un punto u objeto (por ejemplo, un primerísimo primer plano o un plano detalle). Por otro lado, es el espectador quien controla el punto de vista.

Teniendo en cuenta estas dos consideraciones, en el reportaje en vídeo en $360^{\circ}$ existen dos modos de guiar la atención del espectador mediante el movimiento de objetos diegéticos:

1) atención guiada con cámara fija: En estos casos, el pedestal de la cámara no se mueve y se utiliza el desplazamiento de uno o varios objetos, animales y/o personas para tratar de dirigir la mirada del espectador hacia el lugar deseado. En el reportaje publicado por la BBC en noviembre de 2016, "Snow leopards in $360^{\circ}$ - Planet Earth II: Mountains", aparecen varios animales de carga en el área izquierda que se desplazan hacia la derecha con el propósito de que el espectador mire allí. De este modo, se asegura la continuidad entre escenas ya que, al pasar a la siguiente, el espectador estará mirando hacia un área de interés, desde la que descienden dos personas.

Centrarse en los objetos cercanos ha sido un factor clave para la supervivencia del ser humano. Como sostiene Itti, "es importante detectar rápidamente presas, depredadores o compañeros potenciales en un mundo visual desordenado" (Itti, 2017: 3327). Teniendo en cuenta este sistema de alerta, otra técnica con cámara fija consiste en aproximar a la lente objetos diegéticos en movimiento para tratar de generar así una respuesta en la mirada del espectador.

El reportaje “Lions $360^{\circ}$ ", publicado en 2017 por National Geographic, emplea con éxito este recurso. Una de sus secuencias parte de un plano general en el que aparece una cría de león que se acerca desde el fondo y avanza hacia el frente hasta 
situarse en un primer plano frente al espectador, de modo que parece mirarle. Una vez aquí, se detiene un instante y prosigue el recorrido lentamente hacia la izquierda, un gesto que parece una invitación a seguirle:

Figura 1. Fotograma de "Lions $360^{\circ}$ "

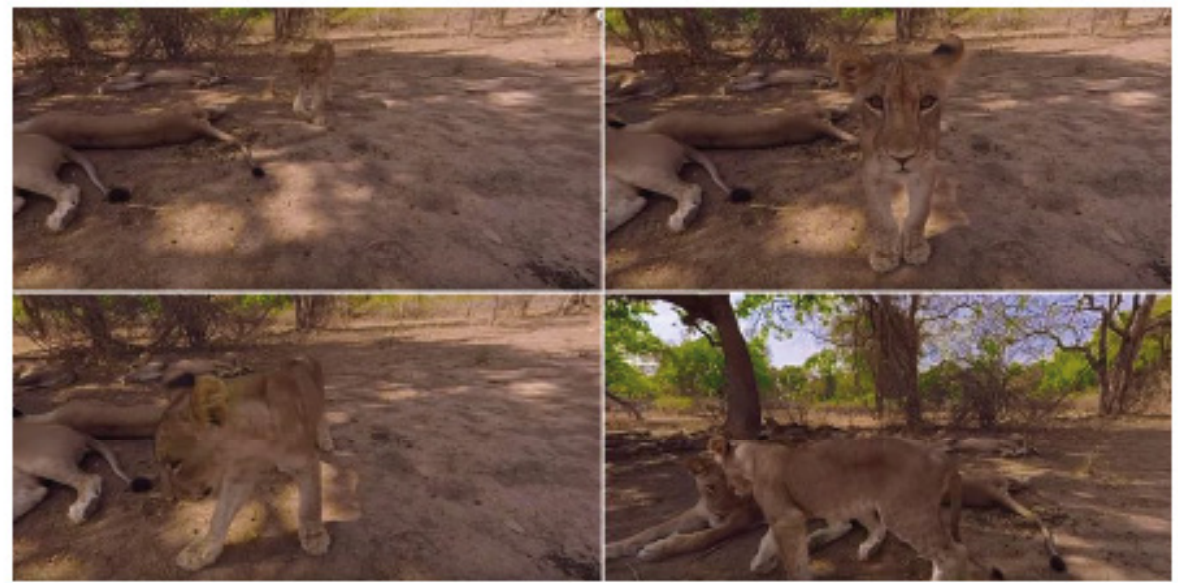

Fuente:YouTube

No obstante, dada la peculiaridad técnica de las cámaras $360^{\circ}$, es importante tener en cuenta la distancia óptima a la que se deben presentar los objetos. Por ejemplo, algunos sistemas de grabación no permiten una aproximación excesiva ya que se podrían producir fallos de paralaje. Según la productora Jaunt Studios, los objetos se deben situar a una distancia de entre 0,7 metros y 9,14 metros respecto a la ubicación de la cámara (Jaunt, 2017: 38).

Otra práctica consiste en situar la acción en un primer plano y excluirla de lo que John Mateer denomina "zonas muertas"; es decir, "áreas de la representación con poca o ninguna actividad o interés visual para promover que el usuario se centre en el área en la que se concentra la acción" (Mateer, 2017: 17). Por ejemplo, en la primera escena del reportaje "A harvest underneath the ice", publicado por The New York Times, la cámara recoge en primer plano la actividad de dos inuits en Canadá abriendo un hueco en el hielo. Detrás de ellos no se desarrolla ninguna acción y sólo se aprecia una extensa capa blanca que no aporta nada a la narrativa por lo que se reduce la capacidad de distracción.

2) atención guiada con cámara en movimiento: Los reportajes inmersivos pueden recurrir a tres movimientos de cámara para dirigir la atención del espectador:

a) Movimiento con cámara en mano: El periodista realiza la grabación al tiempo que camina, transportando la cámara en la mano, sobre un soporte en la cabeza o en un palo. La finalidad de este recurso es obtener un punto de vista subjetivo que trata de recrear el avance del propio espectador dentro de la escena. Si, además, este movimiento se acompaña de la imagen de un personaje que señala un área determinada a través de voces, gestos o de su propio movimiento, será aún más fácil guiar su atención hacia allí. 
Un trabajo en el que se emplea este recurso de manera adecuada es el reportaje "En la piel de un refugiado", donde un personaje "recibe" al espectador en primer plano. Su función es guiarle hacia el centro de refugiados. Para ello se combina su movimiento, dirigido hacia el frente, junto a su voz y diferentes gestos. Así se puede apreciar en la siguiente captura:

Figura 2. Fotograma de "En la piel de un refugiado"

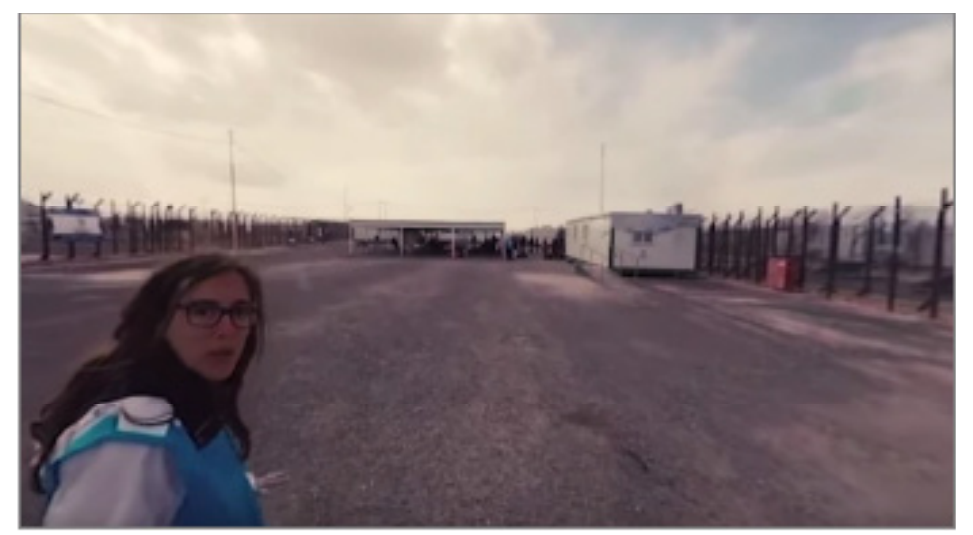

Fuente:YouTube

b) Movimiento con la cámara emplazada sobre un medio de transporte: Otra técnica consiste en colocar la cámara sobre algún medio de transporte para dirigir la atención hacia el frente. Los reportajes inmersivos recurren con frecuencia a esta posibilidad a través de diversos medios de locomoción como aviones, barcas, coches, globos, caballos, etc. Con todo, conviene no abusar de técnicas que incluyan demasiado movimiento ya que podrían generar un efecto negativo y provocar malestar o mareo.

c) Movimiento con la cámara emplazada sobre un sistema dirigido o aéreo. Finalmente, la tercera técnica consiste en colocar la cámara sobre un objeto en movimiento controlado a distancia, que puede estar situado sobre un sistema robotizado, un equipo sobre raíles (travelling), o sobre un objeto volador como un dron, un avión o, incluso, un pájaro. En estos casos, conviene recordar que, aunque el movimiento guiará la atención del espectador, el punto de vista que se va a obtener no va a ser el de una persona, ya que la lente de la cámara no coincidirá con la altura de sus ojos. Esto puede generar un conflicto en cuanto a la sensación de presencia ya que el espectador nunca va a perder su identidad y le puede resultar difícil aceptar una perspectiva tan distinta. Además, al igual que en los casos anteriores, también aquí existe el riesgo de que se genere algún tipo de malestar, por lo que conviene utilizar esta técnica con cierta cautela e incluso informar de ello al comienzo del reportaje.

\subsection{Emplear técnicas adecuadas de iluminación y color}

En otros medios audiovisuales como el cine, la iluminación y el color juegan un papel decisivo a la hora de guiar la atención (Bordwell y Thompson, 1995: 152). En el caso del reportaje inmersivo con vídeo en $360^{\circ}$ encontramos una 
primera dificultad ya que la iluminación se encuentra prácticamente limitada a la luz natural o luz del ambiente puesto que toda la escena en $360^{\circ}$ queda registrada. Por eso, es necesario ocultar todo el material técnico de iluminación que habitualmente se utiliza en los rodajes como focos, grúas, pantallas, pértigas, etc.

Para mitigar este inconveniente, algunos productores recomiendan emplear técnicas de iluminación durante la fase de post-producción (Tecnic, 2018). No obstante, si se aplican durante la grabación se pueden integrar mejor dentro del relato y ofrecen un resultado más natural. La iluminación añadida durante la post-producción resulta más artificial, lo cual puede hacer más evidente la mediación y reducir la sensación de presencia. Asimismo, esta práctica podría generar más de un conflicto ético por la manipulación que implica este proceso. Desde una perspectiva más concreta, las posibilidades de incorporar técnicas de iluminación para guiar la atención durante la grabación son tres:

a) Crear un punto de iluminación a partir de luz ambiente. Para dirigir la atención hacia un área localizada en el centro, se puede recurrir a esta técnica aprovechando la luz natural. Se emplea, por ejemplo, en el reportaje "Life on Mars: preparing for the red planet”, publicado por The New York Times en 2017 que recurre a la luz cenital para guiar la atención hacia la salida de un túnel por el que ascienden dos exploradores.

b) Crear un punto de iluminación a partir de luz artificial. Al igual que en el caso anterior, consiste en destacar un área de la imagen a través de una fuente de luz principal, oscureciendo el resto. No obstante, en este caso, la fuente de luz que se emplea es artificial. Encontramos un uso correcto de esta técnica en el reportaje "Cervantes VR", publicado en 2017 por el Lab de RTVE. En un momento de la narración, el foco de luz principal se dirige hacia la cama en la que convalece Don Quijote. Dado que el resto del escenario se mantiene en fondo negro, se logra concentrar la atención hacia el área visible en la que se encuentra el protagonista.

c) Emplear una fuente de luz secundaria. Algunos reportajes emplean una fuente de luz adicional para dirigir al espectador hacia un área secundaria. Por ejemplo, "At Kochi Biennale, Art imitating death: an artist at work", publicado por The New York Times en 2017, emplea un foco de luz intensa para alumbrar al protagonista de la escena al tiempo que sirve para dirigir la atención hacia éste.

El color también permite guiar la atención. En este sentido, Bordwell y Thompson destacan la "paleta limitada" de colores y el uso del blanco y negro (Bordwell, Thompson, 1995: 164). Estas técnicas se pueden trasladar de modo eficaz a los reportajes inmersivos con vídeo en $360^{\circ}$ con el propósito de guiar la atención:

1) Contraste entre los valores de luminosidad. Aunque los estudios a este respecto no han llegado a resultados concluyentes (Tecnic, 2018: 38), algunos reportajes emplean el color de un modo acertado. Es el caso de “36 hours in Michigan's upper peninsula", publicado por The New York Times en 2017. Sobre un plano en el que predominan los tonos fríos (azul, verde y blanco), se emplea uno cálido que destaca el faro del fondo (rojo) y guía la mirada hacia él. Además, la barandilla sobre el puente que conecta el primer plano con el faro también es roja, lo que actúa como un recurso guía integrado en la narración. 
Figura 3. Fotograma del reportaje " 36 hours in Michigan's upper peninsula”

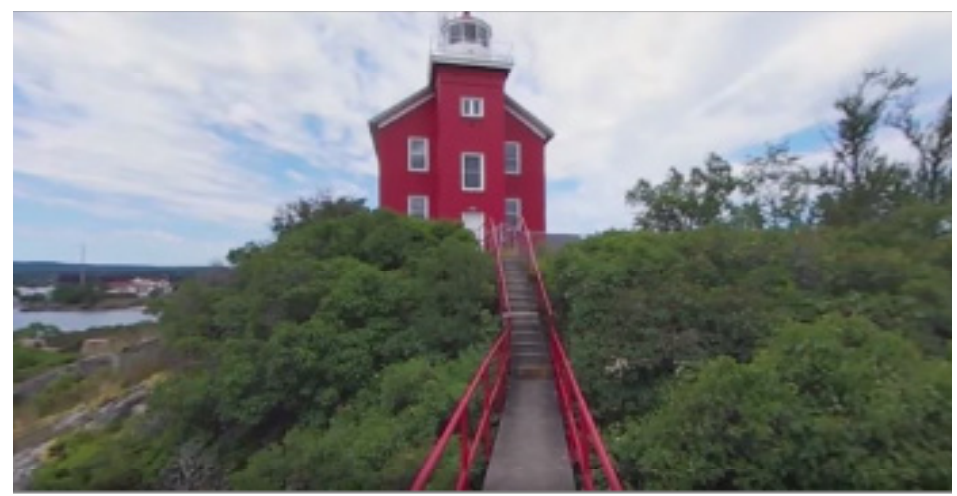

Fuente:YouTube

2) Paleta limitada. Esta técnica consiste en combinar una escala apagada de colores - sin apenas contraste- con un color diferente que resalta sobre el resto de la composición. Se aprecia, por ejemplo, al inicio del reportaje "India Parades: rehearsals ahead of Republic Day celebrations", publicado por Associated Press en 2017. Los adornos amarillos de los gorros de los soldados que avanzan hacia la izquierda contrastan con el color gris de los edificios al fondo, lo que contribuye a que el espectador mire hacia el sentido de su marcha.

3) Uso del blanco y negro. Se puede utilizar para dirigir la atención hacia una zona de la escena más clara u oscura, según domine una u otra, respectivamente. El reportaje "Firsthand account: The assassination of Malcolm X", publicado por The New York Times en 2017, introduce en la escena del asesinato el blanco y negro para señalar un momento del pasado sobre un escenario actual. Junto al blanco y negro, el uso del color rojo sobre la figura del líder político genera un mayor contraste y permite captar hacia él la mirada: 
Figura 4. Fotograma del reportaje "Firsthand account: The assassination of Malcolm X"

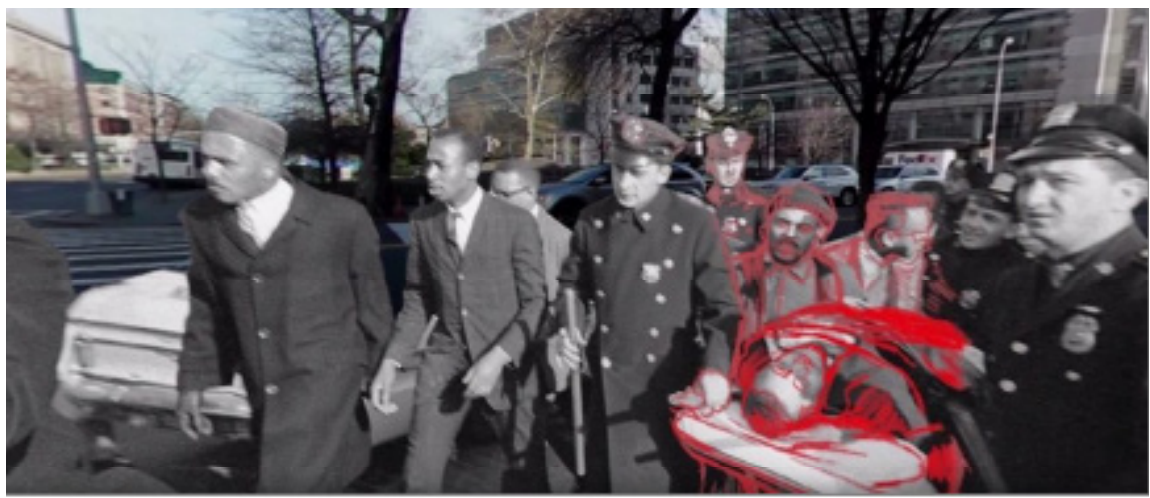

Fuente: YouTube

\subsection{Integrar elementos gráficos en la narración}

Añadir elementos gráficos sobre la escena también puede ser un recurso adecuado para guiar la atención hacia un área concreta. Los resultados obtenidos por Tecnic confirman que esta técnica es más eficaz que las relacionadas con la iluminación y el color. Dentro de los gráficos utilizados en su estudio, destaca el uso de las líneas guía, a las que se refiere como "líneas animadas que comienzan en un punto extremo y se mueven hacia el área importante" (Tecnic, 2018: 16). Éstas se pueden completar con el empleo de cuadros de texto y títulos que "consiguen que los espectadores permanezcan en la dirección en la que están apareciendo a la espera de algo que va a ocurrir” (Tecnic, 2018: 32).

Son muchos los reportajes que recurren a este tipo de elementos gráficos. Destacan los publicados por The New York Times, dentro de la serie titulada "Seven Wonders of the World" que recorre diferentes lugares del mundo. Puesto que se trata de piezas que muestran diversas localizaciones en las que la acción es escasa y no existe narrador, la aparición progresiva de este tipo de elementos son el soporte que guía la mirada del espectador.

No obstante, conviene emplear estos recursos con cierta precaución ya que se trata de elementos artificiales añadidos que restan realismo a la representación y pueden romper la ilusión de presencia (Slater et al., 2009: 202).

Siguiendo a Nielsen y colaboradores, esta artificiosidad se puede reducir a través de elementos diegéticos implícitos, de modo que, aunque el espectador esté siendo guiado, mantiene el control "sin sentirse forzado y sin perder su capacidad de interactuar libremente por la escena" (Nielsen et al., 2016: 230). Así ocurre en "VR highline over an Arizona canyon", publicado por USA Today 2016. El reportaje muestra a un acróbata que camina sobre una cuerda suspendida entre dos picos de una montaña. En este caso, la cuerda, de color verde y por medio de la cual avanza el personaje, dibuja una línea recta que sirve de guía para que el espectador mantenga la mirada en esa dirección. 


\subsection{Aplicar sonidos espaciales a objetos}

Como adelantábamos, en cualquier contenido audiovisual el sonido resulta fundamental. Bordwell y Thompson recuerdan su importancia que ha sido tenido en cuenta ya desde los inicios del cine mudo (Bordwell y Thompson, 1995: 293). Los autores destacan la capacidad de la atención acústica ya que el sonido puede formar una "perspectiva sonora más completa" (Bordwell y Thompson, 2018: 310).

En el reportaje inmersivo con vídeo en $360^{\circ}$ el sonido también puede ser empleado para guiar la atención del espectador. De acuerdo con Biocca y Delaney, el audio en entornos en $360^{\circ}$ puede "alertar al usuario sobre los objetos y seres virtuales y lograr que gire la cabeza en una u otra dirección” (Biocca y Delaney, 1995: 81). Igualmente, Anderson y Casey defienden su importancia a la hora de ayudar al usuario a orientarse en el entorno virtual y recuerdan que resulta conveniente que éste sea espacial (Anderson y Casey, 1997: 46).

Cuando un objeto está detrás del espectador, debería sonar como si estuviera efectivamente allí. Según sostienen Aronson-Rath y sus colaboradores, "al percibir que el audio proviene de la dirección donde están situados los objetos en la pantalla, se genera en el espectador una respuesta sensorial consistente y más creíble” (Aronson-Rath et al., 2015: 66). Igualmente, para Leyveld el sonido "permite al espectador escuchar lo que sucede a su alrededor mientras mira en una dirección" (Leyveld, 2015: 10), lo que le convierte en un factor crucial para guiar la atención dentro del escenario esférico (Rothe y Hußmann, 2018).

En $360^{\circ}$, esta forma de crear un entorno sonoro envolvente, convincente y tridimensional cambia respecto al sonido estereofónico y/o surround que se emplea en vídeo convencional (Bordwell y Thompson, 2018: 311). Por un lado, resulta difícil usar micrófonos direccionales, ya que los equipos empleados durante el rodaje deben desaparecer. Esta limitación se puede superar incorporando sistemas de audio de dimensiones muy reducidas que se ocultan en el equipo de grabación y registran audio binaural ${ }^{5}$ con alta calidad.

Por otro lado, la libertad otorgada al espectador para cambiar el punto de vista implica que, aunque esté mirando hacia un área del escenario, debe escuchar lo que pasa a su alrededor, como ocurriría en un entorno real. Es decir, si un coche aparece por la izquierda, el sonido debe proceder de allí, pero si el espectador se gira hacia la derecha, deberá sonar entonces a su espalda, transmitiendo así la percepción de que se encuentra dentro "de una escena completa en $360^{\circ}$ que se modifica en tiempo real" (Jaunt, 2017: 50).

Rothe y Hußmann (2018) confirmaron la eficacia de los objetos en movimiento y del sonido diegético para atraer y guiar la atención del espectador hacia un área en entornos creados con vídeo en $360^{\circ}$. Además, comprobaron que el sonido resultaba más eficaz cuando iba unido a un objeto y que la eficacia era la misma tanto si el sonido era o no espacial y si provenía o no de otra dirección.

5 El audio binaural hace referencia a la señal de audio que el cerebro humano utiliza para localizar el sonido. Cuando escuchamos sonidos en el entorno, el cerebro recibe varias señales proporcionadas por los oídos que interpreta para ubicar el origen de un sonido en relación con el cuerpo, lo que se conoce como localización (Jaunt, 2017: 51). 
Los entrevistados también destacan la importancia que tiene el audio a la hora de dirigir la atención del espectador:

"El sonido juega un papel fundamental. Se ha experimentado mucho con el sonido ambidireccional: no todos los medios lo usan, lo aplican en sus vídeos, eso es cierto, pero yo creo que juega un papel crucial porque va a ser el modo de guiar al receptor en el mundo narrado" (Pérez-Seijo, 2018).

"El audio es muy importante para guiar la atención ya que funciona como la realidad: cuando a uno le llaman, se da la vuelta" (Sedano, 2018).

"El audio es súper importante. Ahora están haciendo audios estereoscópicos, de tal forma que, si la acción ocurre aquí, te suena desde aquí. Entonces tú te giras porque has escuchado un ruido a tu espalda y eso es fundamental. Luego, también, en parte, el guion puede hacer que guíes hacia dónde tiene que mirar el espectador y si, de repente, dices en un off: 'en un bar el sol brilla con fuerza esta mañana en invierno', pues no va a mirar al suelo. El audio puede ayudar mucho. Es fundamental como recurso que puede contribuir a la inmersión" (Hernanz, 2016).

Otros entrevistados recuerdan que resulta muy conveniente combinar el audio con otros recursos narrativos:

"El sonido espacial permite, si está bien editado, guiar la atención hacia un punto concreto donde se produce. Pero existen otras maneras de dirigir la atención. Por ejemplo, los colores en las imágenes. La atención humana resulta atraída por los objetos brillantes, de modo que acentuar la intensidad de colores en el brillo y en el contraste puede ayudar a guiar la atención" (Baía, 2018).

"Ahí el audio puede dirigir, pero no es cien por cien seguro ya que interviene la curiosidad del espectador. Este reclamo se puede reforzar visualmente añadiendo objetos o personajes en movimiento. Por ejemplo, en un reportaje lo hicimos colocando a un grupo de inmigrantes hablando en un área de la escena para que el espectador mirara hacia allí” (Hernández, 2018).

Al trasladar estas consideraciones al reportaje inmersivo con vídeo esférico se pueden usar dos clases de sonidos para guiar la atención: los efectos sonoros y los recursos de voz.

1) Efectos sonoros: Para que el espectador mire hacia un lugar concreto, será más fácil que lo haga si se produce un sonido que reclame su atención como, por ejemplo, una explosión, el ruido de unos pasos, la sirena de una ambulancia, el ruido de un motor, un aplauso, etc.

Existen diferentes maneras de aplicar esta técnica. Una de ellas consiste en incorporarlo en post-producción, a través de software. Es lo que se hace, por ejemplo, en algunas escenas del reportaje "En la piel de un refugiado". Comienza con una explosión. Inmediatamente después, se suma el ruido de varias sirenas. El espectador, situado frente una puerta, dirige su atención hacia el estruendo de la calle que llega desde una ventana, justo detrás de él. En ese momento, aparece un personaje gritando para que le "acompañe" en la huida. Para verlo, el espectador debe mirar de nuevo hacia la puerta. Para su director, el sonido resulta muy importante en este tipo de proyectos:

"El sistema de grabación de audio tiene que estar situado justo debajo de la cámara, donde va el soporte para que no se vea y por eso tiene que ser espacial. O debe ser espacial. Tiene que abarcar todo lo que está alrededor [...] Pero el sonido es muy importante. Se pueden añadir ruidos para guiar la acción a un punto [...] Si tienes las gafas, automáticamente diriges allí la vista y ves a la persona que está gritando" (Morán, 2016). 
Existe otra técnica que se puede emplear para guiar la atención. En este caso, el audio se registra como parte del sonido ambiente durante la grabación, pero se intensifica durante la post-producción. Encontramos un ejemplo de este uso al inicio del reportaje "Calais migrant camp in 360: seeking home”, publicado en 2015 por la productora Ryot. En la primera escena se introduce un plano en blanco y negro en el que se escucha el sonido del choque del viento contra la lona de una tienda de campaña. La siguiente escena muestra a un refugiado saliendo de la tienda donde duerme. El ruido intenso que hace la cremallera al cerrarse reclama la atención del espectador.

Por medio de técnicas más avanzadas, algunas producciones han empleado sonido binaural para registrar el audio. Con ello se simula el modo en el que los humanos percibimos el sonido y permite que el espectador conozca su localización. Es lo que ocurre en "Dive into le Moulin Rouge", un trabajo publicado por Jaunt, en 2018. Este reportaje muestra una sesión de ensayo de las bailarinas del Moulin Rouge de París. El sonido está localizado donde se produce, pero responde en tiempo real a los movimientos y giros del espectador cuando cambia el punto de vista: cuando mueve la cabeza, no sólo modifica el punto de vista de la imagen, sino que detecta un cambio en la dirección del sonido.

No obstante, incorporar el sonido binaural en un reportaje inmersivo con vídeo en $360^{\circ}$ resulta complejo y costoso. Lo confirma el profesor de la USC Robert Hernández, a partir de su propia experiencia:

"Para el audio compramos un micrófono externo, pero no nos metemos en el audio espacial en 360. Sabemos cómo hacerlo, pero perdemos mucho tiempo porque supone mucho trabajo y no está garantizado que el público lo vaya a escuchar de esa forma” (Hernández, 2018).

2) Recursos de voz. Otro elemento de audio que ayuda a guiar la atención es la voz humana, que puede provenir de un narrador o de un personaje. Ambos pueden ser elementos diegéticos; es decir, formar parte de la acción que se está representando, si bien, en el caso del narrador, puede ser una figura extradiegética (narrador omnisciente). En este último caso, la mediación se hace más evidente. Por el contrario, el narrador intradiegético, representado por un personaje dentro del acontecimiento, permite acortar la distancia, de modo que su voz se puede interpretar como la de una persona más dentro de la historia.

En ocasiones son los propios protagonistas los que guían de modo eficaz la atención del espectador cuando apelan o se dirigen directamente a él para que mire hacia algún punto. Esta técnica se utiliza en distintos momentos de "En la piel de un refugiado" (Benítez de Gracia y Herrera Damas, 2018b).

También suele ser frecuente recurrir a un narrador extradiegético. El País emplea este recurso en distintos reportajes. En "Así es la vida en los barrios más pobres de Dacca", de enero de 2017, el narrador se dirige en varios momentos al espectador y le indica hacia dónde mirar. 


\section{Discusión y conclusiones}

El reportaje inmersivo con vídeo en $360^{\circ}$ constituye una forma novedosa de contar los acontecimientos periodísticos ligada a la evolución que han experimentado las tecnologías inmersivas en los últimos años. Combinadas, estas tecnologías permiten representar los acontecimientos de un modo inédito y con un alto grado de realismo pues el espectador, al ponerse las gafas VR, accede a un escenario esférico de apariencia tridimensional y desde una perspectiva en primera persona que puede recorrer al mover y girar la cabeza.

Esta novedad ha sido aprovechada por prestigiosos medios periodísticos, tanto nacionales (RTVE, El País, El Español, Castilla La Mancha Media o Canal Extremadura) como internacionales (The New York Times, The Guardian, Associated Press, Frontline, USA Today, BBC, RT, etc.), que han publicado un gran número de este tipo de reportajes en relación con los más diversos temas. El formato también ha captado la atención de una parte de la comunidad académica que, en los últimos cinco años, ha incrementado de un modo notable la producción científica sobre el particular.

Con todo, elaborar este tipo de piezas sigue siendo complejo y costoso. La simplicidad del sistema de grabación para registrar un escenario resulta solo aparente, ya que en la práctica se enfrenta a una serie de dificultades que no se presentan en una grabación audiovisual convencional. Además, éstas surgen ya desde el primer momento de la grabación, que requiere ocultar el equipo técnico y humano para que no quede registrado en la imagen en $360^{\circ}$. Los expertos a los que hemos entrevistado refieren que esta dificultad se va haciendo cada vez mayor conforme avanza el proceso de grabación puesto que no se pueden emplear planos cortos o primeros planos, hay que limitar el movimiento para no generar malestar o mareo en el espectador, no se puede hacer zoom, etc. Todos estos condicionantes obligan al director a replantear algunas de las convenciones audiovisuales. Uno de los interrogantes más urgentes se refiere precisamente al de cómo guiar la atención del espectador en determinados momentos.

La falta de experiencia previa en relación con este tipo de producciones ha forzado a los primeros creadores a aprender sobre la marcha, explorando las diversas posibilidades sobre la base del ensayo y error, tal y como han declarado en las entrevistas. Los expertos coinciden en la importancia que tiene el audio como elemento guía, si bien recuerdan que también es importante combinarlo con otros recursos como la iluminación o el movimiento de objetos y/o sujetos.

A partir de las reflexiones de nuestros entrevistados y de los hallazgos encontrados en la literatura académica, proponemos 4 buenas prácticas que se pueden emplear de forma independiente o combinada. Entre ellas, destacamos el movimiento de personas u objetos ante la cámara, la iluminación, el color, el empleo de elementos gráficos y el uso de sonido espacial. La utilización de estas técnicas resulta más eficaz cuando se trata de elementos diegéticos y se encuentran, por tanto, integrados dentro de la narración, puesto que esto permite que pasen más inadvertidos para el espectador.

Confiamos en que estas buenas prácticas sirvan como una primera guía para aquellos futuros productores que se adentren en este formato si bien somos conscientes de que el desarrollo de este tipo de narrativas pueda replantear el uso y la aparición de otras nuevas.

Por lo demás, la propuesta remite a la necesidad de llevar a cabo futuros estudios de recepción de carácter experimental que puedan certificar el mayor o menor grado de eficacia de estos -y otros- recursos. Al mismo tiempo, también pone de 
manifiesto la necesidad de continuar la investigación académica en relación con otras etapas del proceso de producción como el guionizado, la capación de imágenes, el montaje o la edición.

\section{Referencias bibliográficas}

Anderson, D.B. \& Casey, M.A (1997).“The sound dimension”, en IEEE Spectrum, vol. 34, num. 3, pp. 46-51.

Aronson-Rath, R., Milward, J., Owen, T. \& Pitt, F. (2015). "Virtual reality journalism”, disponible en https://towcenter.org/ research/virtual-reality-journalism/

Baía, A. (2018). Entrevista en profundidad llevada a cabo por María José Benítez.

Bailenson, J. 2018. Experience on Demand:What Virtual Reality Is, How It Works, and What It Can Do. 1st ed. New York: WW Norton \& Company.

Benítez, M. J. y Herrera, S. (2017). "El reportaje inmersivo a través de vídeo en $360^{\circ}$ : ventajas, límites y buenas prácticas”, en Torrado, S., Ferreras, J.G.; Ródenas, G. (eds.). Territorios transmedia y narrativas audiovisuales. Barcelona: UOC, pp. 165-189.

Benítez, M. J. y Herrera, S. (2018a). “Los primeros pasos del reportaje inmersivo a través de vídeos en 360”, en Historia y Comunicación Social, vol. 23, núm. 2, pp. 547-566, https://revistas.ucm.es/index.php/HICS/article/view/62784

Benítez de Gracia, M. J. y Herrera Damas, S. (2018b). “Inmersión del espectador en el reportaje en $360^{\circ}$. Análisis comparativo de ‘En la piel de un refugiado’ y ‘Fukushima, vidas contaminadas’”, en Doxa Comunicación, núm. 26, pp. 191-210, https:// doi.org/10.31921/doxacom.n26a9

Benítez de Gracia, M. J. y Herrera Damas, S. (2020). Cómo producir reportajes inmersivos con vídeo en 360. Barcelona: UOC.

Biocca, F. \& Levy, M.R. (1995). Communication in the age of virtual reality. Hillsdale: Lawrence Erlbaum Associates.

Bordwell, D. \& Thompson, K. (1995). El arte cinematográfico: Una introducción. Barcelona: Paidós.

Brillhart, J. (2016). "In the blink of a mind attention", en Medium, disponible en https://medium.com/the-language-ofvr/in-the-blink-of-a-mind-attentionlfdff60fa045 [2018-04-27].

Clark, L. (2015). “Total immersion: How VR is transforming everything from education to medicine”, en Wired Magazine, disponible en http://www.wired.co.uk/magazine/archive/2015/07/features/v r-total-immersion

Coloma, J. (2016). Entrevista en profundidad llevada a cabo por María José Benítez.

Colussi, J. y Assunção Reis, T. (2020). "Periodismo inmersivo. Análisis de la narrativa en aplicaciones de realidad virtual”, en Revista Latina de Comunicación Social, núm. 77, pp. 19-32, https://doi.org/10.4185/RLCS-2020-1447

Conesa, X. (2016). Entrevista en profundidad llevada a cabo por María José Benítez. 
De la Peña, N.; Weil, P.; Llobera, J.; Spanlang, B.; Friedman, D.; Sánchez-Vives, M.V.; Slater, M. (2010). "IJ: Immersive virtual reality for the first-person experience of news", en Presence: Teleoperators and Virtual Environments, vol. 19, num. 4, pp. 291-301.

Dolan, D. \& Parets, M. (2015). "Redefining the axiom of story: The VR and 360 video complex", en Medium, disponible en https://medium.com/@devon.michael/redefining-the-axiom-of-story-the-vr-and-360-video-complex-bee3c20d69df

Domínguez, E. (2010). “Los nuevos formatos inmersivos y su aplicación en el periodismo”, en II Congreso Internacional de Ciberperiodismo y Web 2.0, celebrado en Bilbao del 10 al 12 noviembre.

Domínguez, E. (2013a). Periodismo inmersivo. Fundamentos para una forma periodística basada en la interfaz y en la acción. Tesis Doctoral defendida en la Universidad Ramón Llull. Barcelona: Universidad Ramon Llull.

Domínguez, E. (2013b). Periodismo inmersivo: La influencia de la realidad virtual y del videojuego en los contenidos informativos. Barcelona: UOC.

Domínguez, E. (2017). "Going Beyond the Classic News Narrative Convention: The Background to and Challenges of Immersion in Journalism”, en Frontiers in Digital Humanities, vol. 4, pp. 1-10

Doyle, P., Gelman, M. \& Gill, S. (2016). "Viewing the Future? Virtual Reality in Journalism”, en Knight Foundation y USA Today, disponible en http://www.knightfoundation.org/media/uploads/publication_pdfs/VR_report_web.pdf

Dwight, L. (2016). “These VR film tips show how to direct audience attention”, disponible en https://uploadvr.com/ vr-film-tips-guiding-attention/

Facebook (2014). "Facebook to acquire Oculus", en Newsroom, disponible en https://newsroom.fb.com/news/2014/03/ facebook-to-acquire-oculus/

Facebook (2015). "Introducing 360 video on Facebook", en Newsroom, disponible en https://newsroom.fb.com/ news/2015/09/introducing-360-video-on-facebook/

Fagan, K. (2018). “Here's what happens to your body when you've been in virtual reality too long”, en Business Insider, disponible en https:/ /www.businessinsider.com/virtual-reality-vr-side-effects-2018-3

Ferrando, I. (2016). Entrevista en profundidad llevada a cabo por María José Benítez.

Gregory, S. (2016). "Immersive witnessing: From empathy and outrage to action", en Witnes, disponible en https://blog. witness.org/2016/08/immersive-witnessing-from-empathy-and-outrage-to-action/

Goldstein, E.B. (2007). Sensation and Perception. Belmont: Wadsworth Pub Co.

Google (2015). “Cardboard”, en Google, disponible en https://developers.google.com/vr/discover/cardboard

Google (2016). "Daydream View coming to stores November 10th”, en Google, disponible en http://www.blog.google/ products/google-vr/daydream-view-coming-stores-november-10th 
Hardee, G. M. \& McMahan, R. P. (2017). “FIJI: A Framework for the Immersion-Journalism Intersection”, en Frontiers ICT, vol. 4, pp. 1-21.

Hernanz, M. (2016). Entrevista en profundidad llevada a cabo por María José Benítez.

Hernández, R. (2018). Entrevista en profundidad llevada a cabo por María José Benítez.

Itti, L. (2017). "Visual salience”, en Scholarpedia Journal, vol. 2, num. 9, p. 3327.

Jaunt (2017). "The cinematic VR Field Guide. A guide to best practices for shooting 360", disponible en https://www. jauntvr.com/cdn/uploads/jaunt-vr-field-guide.pdf

Jones, S. (2017). "Disrupting the narrative: immersive journalism in virtual reality", en Journal of Media Practice, vol. 18, nums. 2-3, pp. 171-185, doi: 10.1080/14682753.2017.1374677

Kent, T. (2015). “An ethical reality check for virtual reality journalism”, en Medium, disponible en https://medium.com/@ tjrkent/an-ethical-reality-check-for-virtual-reality-journalism-8e5230673507

Kool, H. (2016). "The ethics of immersive journalism: a rhetorical analysis of news storytelling with virtual reality technology", en Intersect, vol. 9, pp. 1-11.

Lelyveld, P. (2015). "Virtual Reality Primer with an Emphasis on Camera-Captured VR", en Motion Imaging Journal SMPTE, vol. 124, num. 6, pp. 78-85.

Macknik, S. y Martínez Conde, S. (2012). Los engaños de la mente. Barcelona: Destino.

Madary M. \& Metzinger, T. K. (2016). "Real virtuality: A code of ethical conduct. recommendations for good scientific practice and the consumers ofVR-technology”, en Frontiers in Robotics and AI, vol. 3, num. 3, doi: 10.3389/frobt.2016.00003

Marconi, M. \& Nakagawa, T. (2017). "Report: How virtual reality will impact journalism”, en Associated Press, disponible en https://insights.ap.org/industry-trends/report-how-virtual-reality-will-impact-journalism

Martínez Rodríguez, L. y Torrado Morales, S. (2017). "Reflexiones en torno al periodismo y la narrativa transmedia", en Torrado, S., Ródenas, G. y Ferreras, J.G. (eds.). Territorios transmedia y narrativas audiovisuales. Barcelona: UOC, pp. 145-164.

Mateer, J. W. (2017). "Directing for Cinematic Virtual Reality: how traditional film director's craft applies to immersive environments and notions of presence", en Journal of Media Practice, vol. 18, num. 1, pp. 14-25, disponible en https:/ / www. researchgate.net/publication/317030610_Directing_for_Cinematic_Virtual_Reality_how_traditional_film_director\%27s_ craft_applies_to_immersive_environments_and_notions_of_presence

Morán, A. (2016). Entrevista en profundidad llevada a cabo por María José Benítez.

Narciso, D., Bessa, M.; Melo, M.; et al. (2019). "Immersive $360^{\circ}$ video user experience: impact of different variables in the sense of presence and cybersickness”, en Univ. Access Inf. Soc., num. 18, pp. 77-87.

Nash, K. (2018). "Virtual reality witness: exploring the ethics of mediated presence", en Studies in Documentary Film, vol. 12, num. 2, pp. 119-131. 
Nielsen, L.T., Møller, M.B., Hartmeyer, S.D., Ljung, T.C.M., Nilsson, N.C., Nordahl, R. \& Serafin, S. (2016). "Missing the point: an exploration of how to guide users' attention during cinematic virtual reality", en Proceedings of the 22nd ACM Conference on Virtual Reality Software and Technology, ACM, pp. 229-232.

Oculus (2014). "Introducing the Samsung Gear VR Innovator edition”, en Oculus, disponible en https://www.oculus.com/ blog/introducing-the-samsung-gear-vr-innovator-edition/

Oculus (2015). “First look at the Rift, Shipping Q1 2016”, en Oculus, disponible en https://www3.oculus.com/en-us/blog/ first-look-at-the-rift-shipping-q1-2016

Oculus (2017). "Best practices guide", en Oculus, disponible en https://developer.oculus.com/design/latest/concepts/ bp_intro/

Pavlik, J. (2005). El periodismo y los nuevos medios de comunicación. Barcelona: Paidós.

Peck, T., Fuchs, H. \& Whitton, M. (2009). "Evaluation of Reorientation Techniques and Distractors for Walking in Large Virtual Environments", en Visualization and Computer Graphics, vol. 15, num. 3, pp. 383-394.

Pérez Seijo, S. (2018). Entrevista en profundidad llevada a cabo por María José Benítez.

Pérez-Seijo, S. y López-García, X. (2019). “La ética del periodismo inmersivo a debate”, en Hipertext.net, núm. 18, pp. 1-13, doi: 10.31009/hipertext.net.2019.i18.01

Pryor, L. (2010). “Immersive news technology: beyond convergence”, en Online Journalism Review, disponible en http:// www.ojr.org/ojr/technology/1017962893.php

Rothe, S. \& Hußmann, H. (2018). "Guiding the viewer in cinematic virtual reality by diegetic cues", en Lecture Notes in Computer Science, 10850, pp. 101-117.

Salaverría, R. (2015). "Innovar en prensa: dónde, cómo y por qué", en AEDE: Libro Blanco de la Prensa Diaria. Madrid: Asociación de Editores de Diarios Españoles, pp. 149-154.

Sánchez Laws, A.L. (2019). Conceptualising immersive journalism. London: Routledge Focus.

Sánchez Laws A.L. \& Utne T. (2019). "Ethics guidelines for immersive journalism”, en Frontiers in Robotics and AI, vol. 6, num. 28, doi: 10.3389/frobt.2019.00028

Sedano, J. (2018). Entrevista en profundidad llevada a cabo por María José Benítez.

Sidorenko, P; Cantero-De-Julián, J.I. y Herranz de la Casa, J.M. (2017). "La realidad virtual y el formato multimedia en $360^{\circ}$ como mecanismo de enriquecimiento de los contenidos periodísticos”, en Sierra, J. (coord.). Nuevas tecnologías audiovisuales para nuevas narrativas interactivas digitales en la era multidispositivo. Madrid: Mc Graw Hill, pp. 99-108.

Sidorenko Bautista, P., Herranz de la Casa, J.M., \& Cantero de Julián, J.I. (2020). "Use of New Narratives for COVID-19 reporting: from $360^{\circ}$ videos to ephemeral TikTok videos in online media”, en Trípodos, núm. 47(1), pp. 105-122.

Sirkkunen, E.; Väätäjä, H.; Uskali, T. \& Rezaei, P.P. (2016). "Journalism in virtual reality: Opportunities and future research challenges", en Academic MindTrek'16: Proceedings of the 20th International Academic Mind Trek Conference. New York: Association for Computing Machinery, pp. 297-303. 
Syrett, H., Calvi, L. \& Van Gisbergen, M. (2017). "The Oculus Rift Film Experience: A Case Study on Understanding Films in a Head Mounted Display", en Intelligent Technologies for Interactive Entertainment: 8th International Conference, INTETAIN, Utrecht, The Netherlands, June 28-30, Springer, pp. 197-208.

Tecnic, A. (2018). Guidance in a 360-degree video with the help of special effects. Attracting attention to a specific object or segment in a 360-degree video using graphical elements, lights, and colours. Tesis de licenciatura defendida en la Universidad de Linnaeus (Suecia), disponible en http://lnu.diva-portal.org/smash/get/diva2:1247362/FULLTEXT01.pdf Uskali, T.; Sirkkunen, E.; Kelling, Ch.; Ikonen, P. \&Väätäjä, H. (2019). “Testing immersive journalism experiences: Emotions and ethics", paper presented at The Future of Journalism conference, Cardiff University.

Uskali, T.; Gynnild, A.; Jones, S. \& Sirkkunen, E. (2021). Immersive Journalism as Storytelling: Ethics, Production, and Design. London: Routledge.

Veas, E., Méndez, E., Feiner, S. \& Schmalstieg, D. (2011). "Directing attention and influencing memory with visual saliency modulation", en Proceedings of the SIGCHI Conference on Human Factors in Computing Systems. ACM, pp. 1471-1480.

Watson, Z. (2017). "VR for News: The New Reality? Digital News Project”, en Reuters Institute, disponible en https://www. digitalnewsreport.org/publications/2017/vr-news-new-reality/

Wimmer, R. \& Dominick, J. (1996). La investigación científica de los medios de comunicación: una introducción a sus métodos. Barcelona: Bosch. 